\title{
GMR
}

\section{Variability of Colletotrichum spp in common bean}

\author{
S.F. Mota, Q.L. Barcelos, M.A. Dias and E.A. Souza \\ Departamento de Biologia, Universidade Federal de Lavras, Lavras, MG, Brasil \\ Corresponding author: E.A. Souza \\ E-mail: easouza@dbi.ufla.br
}

Genet. Mol. Res. 15 (2): gmr.15027176

Received September 14, 2015

Accepted December 4, 2015

Published April 7, 2016

DOI http://dx.doi.org/10.4238/gmr.15027176

ABSTRACT. The Colletotrichum genus presents large genetic variability, as demonstrated by the occurrence of several pathogenic races and phenotypic traits. The objective of this study was to characterize 22 strains of $C$. lindemuthianum and Colletotrichum spp recovered from anthracnose lesions and bean scab, and to verify the relationship between species of the Colletotrichum genus, which inhabit anthracnose and scab lesions. Colony morphology, conidium size, the presence of septa, germination, sporulation, and mycelium growth rates, were analyzed in addition to the presence of mating-type genes, IRAP markers, and pathogenicity. Strains of Colletotrichum spp presented wide variation for all evaluated traits, indicating the presence of different species. Pathogenicity tests verified that the severity of the disease caused by strains of Colletotrichum spp must be evaluated 17 days after inoculation. Molecular analysis showed that only the $C$. lindemuthianum strains were grouped by the IRAP markers. For the physiological traits, we observed that $C$. lindemuthianum mycelium growth is slower than that of Colletotrichum spp strains. The information generated in this study confirms variability in the evaluated species of Colletotrichum and may direct future basic and applied studies aiming to control these diseases in common bean.

Key words: Colletotrichum lindemuthianum; Genetic variability; Glomerella spp; Scab bean; Anthracnose 


\section{INTRODUCTION}

Anthracnose is one of the main fungal diseases in common bean and leads to large losses in yield and grain quality. The disease is caused by the anamorphic form of the fungus Colletotrichum lindemuthianum, which presents wide variability in its populations (Pinto et al., 2012). In addition to anthracnose, the occurrence of common bean scab has been observed in experimental and production fields of common bean. Both diseases can occur simultaneously in the same plant tissue and each disease has symptoms that can be mistaken for those of the other, especially in the leaves and stem. There is little information on common bean scab, and a careful investigation is required with regards to Colletotrichum truncatum, which is reported to be the causal agent.

The Colletotrichum genus exhibits wide genetic variability and, in addition to sexual recombination, other mechanisms such as the parasexual cycle exist that allow the transfer of genetic material (Castro-Prado et al., 2007) and asexual recombination through conidial anastomosis tubes (CATs) (Roca et al., 2003; Ishikawa et al., 2012). High variability has been observed in morphological and physiological traits, and several of these are important for pathogen development and survival, such as mycelial growth rate, colony diameter, sporulation capacity, and percent germination (Souza et al., 2007). Another important trait used in taxonomy of the genus Colletotrichum is the cytology of the conidia and the presence of septa in the germinated conidia, the latter of which is an important morphological marker (Souza et al., 2007).

The activity of transposable elements can generate genetic variability in fungi (Daboussi and Capy, 2003). Retrotransposons, which use RNA as an intermediate during transposition, are the most abundant elements in the genome and may be divided into families, which may exhibit polymorphism and, therefore, be used as molecular markers (Wicker et al., 2007). Interretrotransposon-amplified polymorphisms (IRAP) are an example of such a marker, i.e., a marker between two retrotransposons of the same family (Kalendar et al., 1999). This marker has been used by Dos Santos et al. (2012) in strains of C. lindemuthianum and has proven to be effective for grouping strains within different races. In addition, this marker has shown promise in studies on intra- and interspecific variability in the Colletotrichum genus (Santana et al., 2013).

Strains of Glomerella sp have been obtained from anthracnose lesions, and these strains have been investigated through their morphological, cytological, molecular, and pathogenic characterization (Barcelos et al., 2014). Those authors identified two distinct groups of Glomerella sp strains collected from anthracnose lesions in common bean, called Glomerella spp groups I and II. Group I strains do not cause symptoms in common bean and cannot be amplified by the HMGglo primers (Barcelos et al., 2011), whereas group II strains lead to mild symptoms 10 days after inoculation and cannot be amplified with the HMGglo primer.

Due to the co-occurrence of bean scab and anthracnose symptoms, and their similarity in common organs of bean plants in the field, in the present study, a comparative analysis was performed between C. lindemuthianum strains and Glomerella strains from groups I and II (Barcelos et al., 2014) collected from anthracnose lesions in common bean and strains of Colletotrichum spp derived from lesions of common bean scab. In addition, we compared the pathogenicity of strains comprising Glomerella sp group II and Colletotrichum spp from common bean scab in two hosts; common bean and soybean plants.

\section{MATERIAL AND METHODS}

The study was conducted in the Plant Disease Resistance Laboratory, in the Molecular 
Genetics Laboratory and in the greenhouse, located in the Biology Department at the Universidade Federal de Lavras, Lavras, MG, Brazil.

\section{Isolates and culture conditions}

Strains of Colletotrichum spp were obtained from naturally infected pods, leaves, and stems of common bean (Phaseolus vulgaris) cultivars. Collections were made in 2009 and 2013 in Minas Gerais, Brazil. Small pieces of infected plant tissues were sterilized and transferred on Petri dishes containing M3 culture medium (Junqueira et al., 1984). In total, 22 monoascosporic cultures were analyzed and divided into four groups; C. lindemuthianum group collected from anthracnose lesions, Glomerella sp groups I and II containing the strains obtained from anthracnose lesions and characterized by Barcelos et al. (2014), and Colletotrichum spp group collected from common bean scab (Table 1).

All strains were maintained in $\mathrm{M} 3$ culture medium at $22^{\circ} \mathrm{C}$ in the dark. After growth, the color of the cultures and the formation of perithecia and ascospores were evaluated.

Table 1. Codes of the 22 strains, their race, country of origin, and group of species analyzed.

\begin{tabular}{|c|c|c|c|c|}
\hline No. & Strain & Race & Country & Group of species \\
\hline 1 & LV134 & 65 & Lambari & C. lindemuthanum \\
\hline 2 & LV145 & 65 & Lambari & C. lindemuthanum \\
\hline 3 & LV153 & 81 & Lambari & C. lindemuthanum \\
\hline 4 & LV175 & 65 & Lavras & C. lindemuthanum \\
\hline 5 & LV228 & 89 & Lavras & C. lindemuthanum \\
\hline 6 & LV238 & 65 & Lavras & C. lindemuthanum \\
\hline 7 & G7-2 & 0 & Lavras & Glomerella sp I \\
\hline 8 & G8-1 & 0 & Lavras & Glomerella sp I \\
\hline 9 & G15-5 & 0 & Lambari & Glomerella sp I \\
\hline 10 & G25-1 & 0 & Lambari & Glomerella sp I \\
\hline 11 & G43-2 & 0 & Lambari & Glomerella sp I \\
\hline 12 & G68-1 & 0 & Lavras & Glomerella sp I \\
\hline 13 & G85-1 & - & Lavras & Glomerella sp II \\
\hline 14 & G86-1 & - & Lavras & Glomerella sp II \\
\hline 15 & G89-1 & - & Lavras & Glomerella sp II \\
\hline 16 & G92-1 & - & Lavras & Glomerella sp II \\
\hline 17 & G93-1 & - & Lavras & Glomerella sp II \\
\hline 18 & G99-1 & - & Lavras & Glomerella sp II \\
\hline 19 & S1 & - & Lambari & Colletotrichum spp \\
\hline 20 & $\mathrm{~S} 2$ & - & Lambari & Colletotrichum spp \\
\hline 21 & S5 & - & Lambari & Colletotrichum spp \\
\hline 22 & S6 & - & Lambari & Colletotrichum spp \\
\hline
\end{tabular}

\section{Index of mycelial growth rate (IMGRs) and colony diameter}

Experiments were carried out in a completely randomized design (CRD) with four replicates. Each plot consisted of one Petri dish. Mycelial plugs (6 $\mathrm{mm}$ in diameter) from the second subculture were placed in the middle of M3 plates, which were incubated in the dark at $22^{\circ} \mathrm{C}$. IMGR was evaluated by taking the average colony measurements (in $\mathrm{mm}$ ) in two perpendicular directions every $24 \mathrm{~h}$ over 15 days and were estimated according to the equation presented by Oliveira (1991). Colony diameter was assessed by taking the average perpendicular diameter of each colony (in $\mathrm{cm}$ ) after 15 days. 


\section{Sporulation capacity}

Sporulation capacity was analyzed in a CRD with two replicates. Each of the 22 strains was inoculated on a PDA Petri dish and incubated at $22^{\circ} \mathrm{C}$ for 14,15 , and 16 days in the dark. Each plot consisted of one Petri dish. Conidial suspensions were obtained by adding $7 \mathrm{~mL}$ sterile water and filtering the suspension through Miracloth. Concentrations were determined by analysis of $10 \mu \mathrm{L}$ of each conidial suspension according to the method described by Dias (2002), using a metallized hemacytometer (Hausser Scientific Company, Horsham, PA, USA).

\section{Characterization of conidia, percentage germination, and anastomosis among conidia}

Conidial suspensions $\left(1.2 \times 10^{6}\right.$ conidia/mL) from 15-day-old C. lindemuthianum cultures and 10-day-old cultures of other strains were prepared as described above. After that, $200 \mu \mathrm{L}$ of each suspension was placed in an 8-well slide culture chamber (Nalge Nunc International, Rochester, NY, USA) and incubated at $22^{\circ} \mathrm{C}$ in darkness for $24 \mathrm{~h}$. Calcofluor White (0.12 M; SigmaAldrich, St. Louis, MO, USA) was added to each well, and the samples were examined after 3-4 min at room temperature using an inverted epifluorescence microscope (Zeiss Axio Observer Z1). Fluorescence was detected at $420 / 70 \mathrm{~nm}$ using the $40 \mathrm{X}$ objective lens. Images from the epifluorescence microscope were captured and processed using the Zeiss Axiovision software. Images from interference contrast microscopy (Zeiss Axio Observer Z1) were obtained using the method described by Damm et al. (2007).

For cytological measurements, 30 non-germinated conidia from each strain were analyzed using a CRD. The width and length of the conidia $(\mu \mathrm{m})$ were obtained using the Zeiss Axiovision software. Germinated conidia from each strain were classified according to the presence or absence of septa. For the percentage germination assays, an experiment in a CRD was carried out in a split-plot design time, with two replications. For each strain, $200 \mu \mathrm{L}$ conidial suspension (1.2 x $10^{6}$ conidia/mL) was placed in 8-well slide culture chambers as previously described. After 24and $48-\mathrm{h}$ culture at $22^{\circ} \mathrm{C}$ in the dark, 100 conidia per replication were evaluated under an optical microscope. Conidium germination was defined as the germ tubes presenting a larger or equal size to the smallest conidial diameter. CAT fusion was quantified as the percentage of conidia or conidium germlings involved in fusions (Ishikawa et al., 2010). Two replications were used for this analysis, with 100 conidia/replicate, after $24 \mathrm{~h}$ of incubation.

\section{Pathogenicity test}

Ten strains were used for pathogenic evaluation; the four groups of Colletotrichum spp strains (S1, S2, S5, and S6) and the six strains from Glomerella sp II (G85-1, G86-1, G89-1, G92-1, G931, and G99-1). Three common bean cultivars (Majestoso, Pérola, and Talismã) and three soybean cultivars (CD202, CD237, and Favorita) were used for the pathogenicity test. Strains were grown on Petri dishes with PDA for $10-15$ days at $22^{\circ} \mathrm{C}$ in the dark to obtain high sporulation rates. Experiments were conducted for each strain in a CRD with six treatments (cultivars) and two replications. Each plot consisted of nine plants. Ten-day-old seedlings with fully expanded primary leaves were sprayed with a conidial suspension $\left(1.2 \times 10^{6} \mathrm{conidia} / \mathrm{mL}\right)$. Inoculated plants were incubated at $23^{\circ} \mathrm{C}$ and $80 \%$ relative humidity. Disease severity was evaluated $7,10,14$, and 17 days after inoculation using the scoring scale proposed by Schoonhoven and Pastor-Corrales (1987) (Table 2). 
Table 2. Score and symptoms of severity of disease of the scale proposed by Schoonhoven and Pastor-Corrales (1987).

\begin{tabular}{l|l}
\hline Score & Symptoms \\
\hline 1 & Absence of symptoms \\
\hline 2 & Up to 1\% of the leaf veins affected, visible only on the lower leaf surface \\
\hline 3 & Up to 3\% of the leaf veins affected, visible only on the lower leaf surface \\
\hline 4 & Up to 1\% of the leaf veins affected, visible on both surfaces of the leaves \\
\hline 5 & Up to 3\% of the leaf veins affected, visible on both surfaces of the leaves \\
\hline 7 & Leaf veins affected, visible on both leaf surfaces, and the presence of some lesions on stems, branches, and petioles \\
\hline 8 & $\begin{array}{l}\text { Necrotic spots on most of the leaf veins and in a large part of the adjacent mesophyll tissue, which ruptures, as well } \\
\text { as the presence of abundant lesions on the stem, branches, and petioles }\end{array}$ \\
\hline 9 & $\begin{array}{l}\text { Necrotic spots on almost all the leaf veins and very abundant on stems, branches, and petioles, leading to ruptures, } \\
\text { leaf shedding, and reduction of plant growth }\end{array}$ \\
\hline
\end{tabular}

\section{Sexual and mycelial compatibility}

Mycelial discs from all strains were paired in all possible combinations on plates containing PDA medium. Mycelial plugs, $6 \mathrm{~mm}$ in diameter were placed $2 \mathrm{~cm}$ apart, with two repetitions per confrontation. Confrontations were evaluated after 15 days of incubation in the dark. Sexual compatibility was indicated by the formation of a dark line of perithecia at the junction of the colonies. Mycelial compatibility was characterized by the mycelial mixture in the contact zone between two colonies.

\section{DNA extraction}

Mycelium plugs were transferred to Erlenmeyer flasks containing $150 \mathrm{~mL}$ M3 liquid medium. The flasks were shaken at $110 \mathrm{rpm} / \mathrm{min}$ at $22^{\circ} \mathrm{C}$ for $3-4$ days in the dark. Mycelia were dried in a vacuum, and subsequently freeze-dried for $48 \mathrm{~h}$.

DNA was extracted according to the methodology described by Raeder and Broda (1985), modified using the methodology described by Kaufman et al. (1999). Aliquots of DNA were quantified on $1 \%$ agarose gels and diluted to $20 \mathrm{ng} / \mu \mathrm{L}$ for subsequent use as working solutions.

\section{PCRs}

\section{Amplification of the HMG region of the mating-type gene MAT1-2-1}

A pair of primers specific to $C$. lindemuthianum were used, namely HMGCLF and HMGCLR, which were described by García-Serrano et al. (2008) and amplify the HMG region of the matingtype gene MAT1-2-1. Because these strains belong to the group of Glomerella sp that do not generate amplification bands when tested with primers specific to $C$. lindemuthianum as described above, a pair of primers specific to these strains of Glomerella sp, HMGGLOF and HMGGLOR, were used (Barcelos et al., 2011). However, as some strains are derived from lesions of common bean scab originated from ascospore, the strains were tested with primers specific to Glomerella truncata, namely CT21HMGF and CT21HMGR (Menat et al., 2012). All gels were treated with ethidium bromide, viewed under ultraviolet light (Fotodyne Ultraviolet Trans-illuminator), and photographed with a digital camera (Kodak EDA-290).

\section{Amplification with primers of IRAP markers}

Markers of terminal direct repeat sequence conserved regions of retroelement $C$. 
lindemuthianum 1 (RetroCl) retrotransposons, exhibiting characteristics of the terminal-repeat retrotransposons in miniature (TRIM) family, were used according to the methodology described by Dos Santos et al. (2012). Two pairs of oligonucleotides were used, the first pair being IRAP1 (5'-CGTACGGAACACGCTACAG-3') and IRAP4 (5'-CTTTTGACGAGGCATGC-3'), and the second pair being IRAP2 (5'-AATAACGTCTCGGCCTTCAG-3') and IRAP4.

\section{Statistical analyses}

Different amplicon patterns were evaluated visually between strains in IRAP analysis. Bands for each combination of initiators used in the selective amplification were identified as 1 (present) or 0 (absent). The reproducibility of DNA band profiles was tested by repetition of the PCR with each of the primers selected. Only bands with reproducibility were considered for analysis. Estimates of genetic similarity $\left(s g_{i j}\right)$ among the strains were carried out by the Sorensen-Dice (Dice, 1945) coefficient method using the program NTSYS - pc 2.1 (Rohlf, 2000). A similarity matrix was used to construct the dendrogram, and cluster analysis was carried out by the unweighted pair group method with arithmetic mean (UPGMA) method (Schneider et al., 2000). Errors associated with each estimate of similarity were estimated using the equation:

$$
\mathrm{S}_{\mathrm{sg}}=\left[\mathrm{sg}_{\mathrm{ij}}\left(1-\mathrm{sg}_{\mathrm{ij}}\right) /(\mathrm{n}-1)\right]^{0.5}
$$

(Equation 1)

where, $n$ is the sum of $a, b$, and c for each pair of strains. Lines belonging to different groups were identified in the dendrogram from the estimate of the maximum significant similarity value $(\mathrm{sgm})$. Sgm was estimated by the $t$-test using the equation:

$$
\operatorname{sgm}=1-(t \text { x sgs })
$$

where, $t$ is the established value of distribution of the Student $t$-test at $1 \%$ probability, with $\mathrm{n}-2$ degrees of freedom, and sgs is the mean error of the comparisons considered.

For the compatibility experiment, a matrix of 0 and 1 was constructed using the compatibility data, considering 0 for incompatible reactions and 1 for compatible reactions. For the estimate of similarity, the coefficient of Russel and Rao (1940) was used through the equation:

$$
\operatorname{sg}_{i j}=a / a+b+c+d
$$

in which, a being compatible for both strains $\mathrm{i}$ and $\mathrm{j}, b$ being compatible only for strain $\mathrm{i}$, and $c$ only for strain $\mathrm{j}$, and $d$ being incompatible for both strains $\mathrm{i}$ and $\mathrm{j}$. A dendrogram was also obtained by the UPGMA method and the strains belonging to different compatibility groups were identified from the estimate of the maximum significant similarity value $(\mathrm{sgm})$.

Analyses of variance were carried out for IMGR, colony diameter, spore dimension, and anastomosis. For germination, analysis of variance was carried out with a split-plot over time. For the sporulation rate and pathogenic analysis, analysis of variance was carried out for each period of evaluation and, afterwards, a combined analysis was performed. For all the characteristics, means were compared by the Scott-Knott test $(P=0.05)$. All analyses of variance, mean tests, and matrices were carried out using the $\mathrm{R}$ statistical software. 


\section{RESULTS}

For all traits, evaluations were carried separately for the $C$. lindemuthianum group and for the group of others.

\section{Colony morphology}

Strains exhibited high variability in colony color and spore formation. Strains belonging to the Glomerella sp I and II groups, derived from anthracnose lesions, exhibited a white and gray color in the initial stages. At 15 days, the colonies turned gray-to-black, and the formation of conidia was observed; these were classified as conidial strains. These colonies formed orange or pink conidial masses, on the surface, except for strains G8-1 and G43-2. These two strains exhibited a white color and the sexual cycle was complete at 15 days, forming perithecia of the "plus" aglomerate type (Edgerton, 1914) with ascospores and the formation of conidial masses. Strains from the $C$. lindemuthianum group showed gray-to-black coloring at the beginning of growth and were totally black at 15 days. Strains from the Colletotrichum spp group, which were derived from bean scab lesions, were white and developed black specks at 15 days. These were observed under a microscope as perithecia, without the presence of spores; i.e., they produced pseudoperithecia. These colonies also produced orange masses of conidia on the surface (Figure 1).
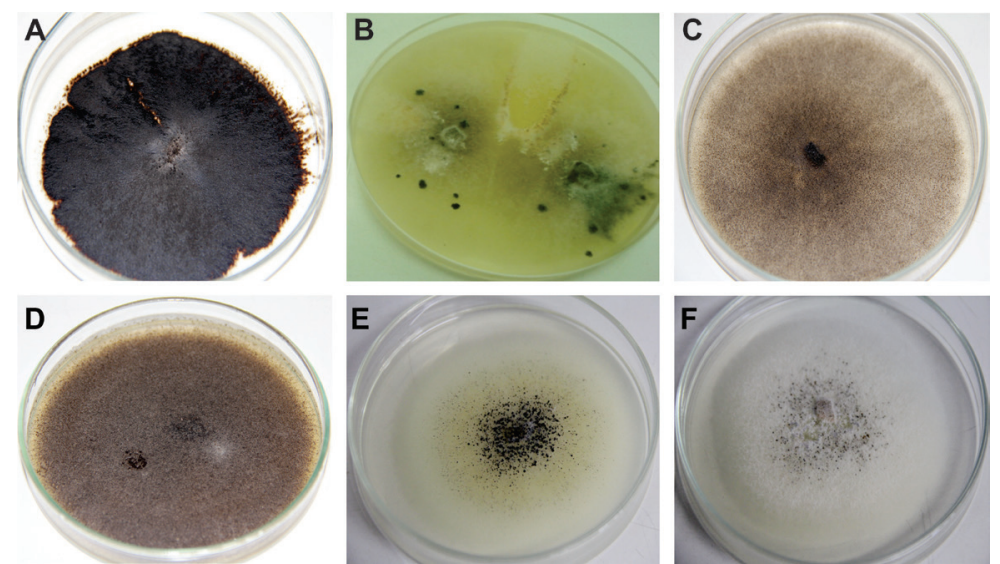

Figure 1. Plates of Colletotrichum. A. Strain LV228. B. Strain G8-1. C. Strain S6. D. Strain 86-1. E. Strain S1. F. Strain S5.

\section{IMGR and colony diameter}

The colony diameter and IMGR were evaluated separately in the $C$. lindemuthianum group and in the group of others. C. lindemuthianum strains were evaluated for 15 days; however, the group of others was only evaluated for 8 days since most of the strains in this group had already reached the total size of the Petri dishes. Strains of $C$. lindemuthianum were grouped into two distinct groups for both traits, whereas the group of others was grouped into two groups for IMGR and five groups for colony diameter. In both groups, variability was high, with the mean IMGR ranging from $2.56 \mathrm{~mm} /$ day (LV228) to $3.92 \mathrm{~mm} /$ day (LV238) for the C. lindemuthianum strains, and from $8.89 \mathrm{~mm} /$ day $(\mathrm{G} 85-1)$ to $10.07 \mathrm{~mm} /$ day (G25-1) for the other strains. As for colony diameter, 
the values ranged from $24.50 \mathrm{~mm}$ (LV153) to $36.25 \mathrm{~mm}$ (LV238) for C. lindemuthianum strains, and $71 \mathrm{~mm}$ (S2) to $80 \mathrm{~mm}$ (G86-1, G89-1, G93-1, G99-1, G7-2, G8-1, G15-5, and G25-1) for the group of others (Table 3 ).

Table 3. Estimated means $( \pm \mathrm{SD})$ of colonial diameter $(\mathrm{mm})$, IMGR $\left(\mathrm{mm} /\right.$ day) and the rate of sporulation $\left(x 10^{6}\right.$ spores $/ \mathrm{mL}$ ) at 14, 15 and 16 days in Colletotrichum lindemuthianum and Colletotrichum spp obtained from lesions of bean anthracnose and scab.

\begin{tabular}{|c|c|c|c|c|c|}
\hline \multirow{2}{*}{ Strains } & \multirow{2}{*}{$\mathrm{DC}^{*}$} & \multirow{2}{*}{ IVCM $^{*}$} & \multicolumn{3}{|c|}{ Sporulation rate* } \\
\hline & & & 14 days & 15 days & 16 days \\
\hline \multicolumn{6}{|c|}{ Strains Colletotrichum lindemuthianum } \\
\hline LV134 & $28.50 \pm 3.11^{\mathrm{B}}$ & $3.29 \pm 0.28^{\mathrm{A}}$ & $0.125 \pm 0.035^{\mathrm{A}}$ & $0.275 \pm 0.035^{\mathrm{B}}$ & $0.2250 \pm 0.035^{\mathrm{B}}$ \\
\hline LV145 & $26.25 \pm 4.65^{\mathrm{B}}$ & $3.37 \pm 0.74^{\mathrm{A}}$ & $0.225 \pm 0.035^{A}$ & $0.150 \pm 0.000^{\mathrm{B}}$ & $0.2750 \pm 0.035^{\mathrm{B}}$ \\
\hline LV153 & $24.50 \pm 1.00^{\mathrm{B}}$ & $3.02 \pm 0.28^{\mathrm{B}}$ & $0.188 \pm 0.017^{\mathrm{A}}$ & $0.575 \pm 0.212^{\mathrm{A}}$ & $0.8250 \pm 0.283^{\mathrm{A}}$ \\
\hline LV175 & $26.50 \pm 6.61^{B}$ & $2.87 \pm 0.53^{\mathrm{B}}$ & $0.138 \pm 0.083^{\mathrm{A}}$ & $0.175 \pm 0.035^{\mathrm{B}}$ & $0.2375 \pm 0.123^{\mathrm{B}}$ \\
\hline LV228 & $27.00 \pm 8.04^{\mathrm{B}}$ & $2.56 \pm 0.57^{\mathrm{B}}$ & $0.175 \pm 0.106^{A}$ & $0.238 \pm 0.053^{\mathrm{B}}$ & $0.2875 \pm 0.053^{\mathrm{B}}$ \\
\hline LV238 & $36.25 \pm 2.63^{\mathrm{A}}$ & $3.92 \pm 0.20^{A}$ & $0.088 \pm 0.017^{A}$ & $0.238 \pm 0.053^{B}$ & $0.1375 \pm 0.018^{\mathrm{B}}$ \\
\hline \multicolumn{6}{|c|}{ Strains Colletotrichum spp } \\
\hline G7-2 & $80.00 \pm 0.00^{A}$ & $9.75 \pm 0.47^{\mathrm{A}}$ & $5.01 \pm 0.85^{\mathrm{B}}$ & $4.14 \pm 0.16^{\mathrm{B}}$ & $2.04 \pm 0.09^{\mathrm{D}}$ \\
\hline G8-1 & $80.00 \pm 0.00^{A}$ & $9.89 \pm 0.14^{\mathrm{A}}$ & $0.72 \pm 0.00^{\mathrm{D}}$ & $0.12 \pm 0.04^{\mathrm{D}}$ & $0.07 \pm 0.04^{\mathrm{G}}$ \\
\hline G15-5 & $80.00 \pm 0.00^{A}$ & $10.07 \pm 0.38^{\mathrm{A}}$ & $0.62 \pm 0.18^{C}$ & $0.66 \pm 0.09^{C}$ & $1.14 \pm 1.26^{\mathrm{E}}$ \\
\hline G25-1 & $80.00 \pm 0.00^{A}$ & $9.79 \pm 0.44^{\mathrm{A}}$ & $0.29 \pm 0.12^{\mathrm{C}}$ & $0.92 \pm 0.07^{\mathrm{C}}$ & $0.36 \pm 0.05^{\mathrm{E}}$ \\
\hline G43-2 & $79.75 \pm 0.50^{A}$ & $9.75 \pm 0.39^{A}$ & $0.10 \pm 0.03^{\mathrm{D}}$ & $0.14 \pm 0.05^{\mathrm{D}}$ & $0.05 \pm 0.00^{\mathrm{G}}$ \\
\hline G68-1 & $79.75 \pm 0.50^{A}$ & $9.43 \pm 0.35^{\mathrm{B}}$ & $4.99 \pm 0.97^{\mathrm{B}}$ & $15.29 \pm 3.09^{A}$ & $11.66 \pm 2.95^{\mathrm{B}}$ \\
\hline G85-1 & $76.00 \pm 2.16^{B}$ & $8.89 \pm 0.32^{\mathrm{B}}$ & $11.18 \pm 8.94^{\mathrm{B}}$ & $26.23 \pm 16.79^{A}$ & $19.82 \pm 4.28^{\mathrm{B}}$ \\
\hline G86-1 & $80.00 \pm 0.00^{A}$ & $9.68 \pm 0.14^{\mathrm{A}}$ & $9.67 \pm 2.43^{B}$ & $15.75 \pm 0.35^{\mathrm{A}}$ & $50.00 \pm 15.56^{A}$ \\
\hline G89-1 & $80.00 \pm 0.00^{A}$ & $9.64 \pm 0.18^{\mathrm{A}}$ & $7.43 \pm 2.93^{\mathrm{B}}$ & $11.58 \pm 2.02^{\mathrm{A}}$ & $22.80 \pm 7.49^{B}$ \\
\hline G92-1 & $79.75 \pm 0.50^{A}$ & $9.64 \pm 0.18^{A}$ & $30.50 \pm 6.36^{A}$ & $14.15 \pm 11.10^{\mathrm{A}}$ & $18.62 \pm 8.66^{\mathrm{B}}$ \\
\hline G93-1 & $80.00 \pm 0.00^{A}$ & $9.93 \pm 0.34^{\mathrm{A}}$ & $0.67 \pm 0.18^{C}$ & $1.00 \pm 0.42^{\mathrm{C}}$ & $1.92 \pm 0.60^{\mathrm{D}}$ \\
\hline G99-1 & $80.00 \pm 0.00^{A}$ & $9.79 \pm 0.27^{A}$ & $1.02 \pm 0.04^{C}$ & $3.75 \pm 1.06^{\mathrm{B}}$ & $5.53 \pm 0.88^{C}$ \\
\hline S1 & $74.25 \pm 0.96^{C}$ & $9.30 \pm 0.96^{\mathrm{B}}$ & $0.54 \pm 0.44^{\mathrm{C}}$ & $1.27 \pm 0.78^{\mathrm{B}}$ & $0.20 \pm 0.14^{F}$ \\
\hline S2 & $71.00 \pm 0.82^{\mathrm{E}}$ & $9.19 \pm 0.82^{\mathrm{B}}$ & $7.25 \pm 3.39^{\mathrm{B}}$ & $15.50 \pm 2.12^{\mathrm{A}}$ & $16.50 \pm 0.71^{\mathrm{B}}$ \\
\hline S5 & $72.00 \pm 2.00^{\mathrm{E}}$ & $9.17 \pm 2.99^{B}$ & $2.55 \pm 0.85^{\mathrm{B}}$ & $3.58 \pm 0.39^{\mathrm{B}}$ & $2.72 \pm 0.88^{\mathrm{D}}$ \\
\hline S6 & $73.00 \pm 0.82^{\mathrm{D}}$ & $9.06 \pm 0.82^{B}$ & $7.85 \pm 0.85^{\mathrm{B}}$ & $7.22 \pm 2.51^{\mathrm{B}}$ & $7.08 \pm 0.11^{\mathrm{C}}$ \\
\hline
\end{tabular}

*Means followed by the same letter belong to the same group $(P<0.05)$ according to the Scott-Knott test.

\section{Characterization of the conidia}

All conidia were cylindrical, except for those from strain $\mathrm{S} 1$, which exhibited a falcate form and gradually tapered to each end, and G43-2 and G8-1, which formed ascospores and exhibited a slightly curved fusiform form (Figure 2 and Table 3 ). 

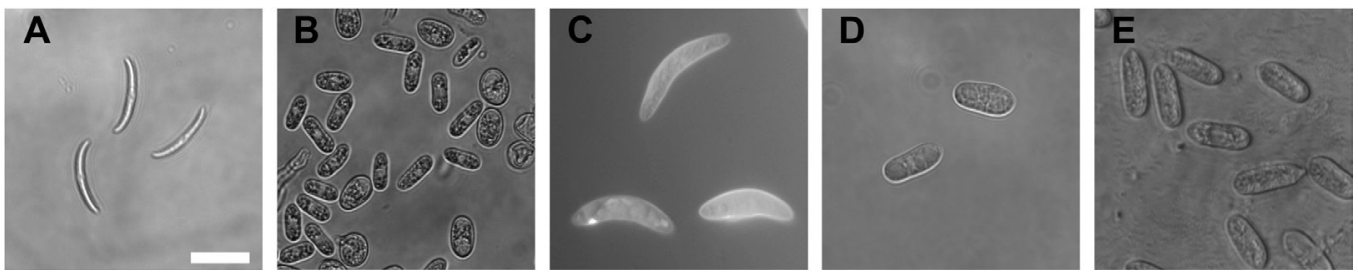

Figure 2. Conidia and ascospores. A. Strain S1. B. Strain G43-2. C. Strain G8-1. D. Strain G85-1. E. Strain LV145. A. Light microscopy and stained with calcofluor. A, B, D, and E. Interference contrast microscopy. Scale A-E $=10 \mu \mathrm{m}$.

Significant differences $(P<0.05)$ were observed for the width and length of conidia. The width of the $C$. lindemuthianum strains ranged from $3.78 \mu \mathrm{m}$ (LV134) to $6.09 \mu \mathrm{m}$ (LV238), forming two groups of statistically distinct strains. Evaluation of the conidium length of the same strains revealed the presence of three distinct groups, with the mean values ranging from $12.58 \mu \mathrm{m}$ (LV228) to $17.47 \mu \mathrm{m}$ (LV145). For the group of others, seven statistically distinct groups were observed for width, and the mean value varied from $2.93 \mu \mathrm{m}$ (G15-5) to $9.3 \mu \mathrm{m}$ (G8-1). For length, the strains were classified into eight distinct groups and varied from $9.05 \mu \mathrm{m}(\mathrm{G} 15-5)$ to $28.94 \mu \mathrm{m}$ (G8-1) (Table 4).

\section{Sporulation capacity}

The strains $x$ period source of variation in ANOVA was significant $(P<0.05)$ for all groups, indicating that the sporulation capacity of the strains was different over the three evaluations. For the $C$. lindemuthianum group, there was no difference in the mean values of the strains at 14 days, whereas at 15 and 16 days, the strains were separated into two distinct groups; nevertheless, only line LV153 was distinct from the others, as it exhibited greater sporulation. For the group of others, the evaluation at 14 and 15 days led to the formation of four groups at each time point, whereas at 16 days, five statistically different groups were formed. In both groups at 16 days, the mean values were greater than on the other days (Table 3 ).

\section{Germination and formation of septa}

For both groups, the strains $x$ period of evaluation interaction was significant $(P<$ 0.05 ), indicating that the percentage germination differed between strains at the two times evaluated. Therefore, the mean values for each strain were compared at 24 and $48 \mathrm{~h}$. For the $C$. lindemuthianum group, the formation of three distinct groups was found at both time evaluated in the comparison of means, and the LV153 strain exhibited greater germination at both at $24 \mathrm{~h}(44 \%)$ and $48 \mathrm{~h}(75.5 \%)$. Strains LV145 and LV238 exhibited the lowest germination rates at $24 \mathrm{~h}(2 \%)$ and $48 \mathrm{~h}(25.5 \%)$, respectively. For the group of others, the formation of six distinct groups was observed at $24 \mathrm{~h}$, ranging from 6\% (G68-1) to $82.5 \%$ (G85-1), whereas seven distinct groups were observed at $48 \mathrm{~h}$, ranging from $26.5 \%$ (S2) to $93 \%$ (G86-1) (Table 4 ). All the strains formed septa during spore germination (Figure 3 ). Nevertheless, not all of the conidia germinated from these strains exhibited septa, and the $\mathbf{S} 1$ strain exhibited more than one septum per germinated conidium, with 0-3 septa. 
Table 4. Morphology of conidia and estimates of means $( \pm \mathrm{SD})$ for the size of conidia $(\mu \mathrm{m})$, anastomosis between conidia (\%), and germination of conidia 24 and $48 \mathrm{~h}$ after inoculation with Colletotrichum lindemuthianum and Colletotrichum spp obtained from lesions of bean anthracnose and scab.

\begin{tabular}{|c|c|c|c|c|c|c|}
\hline \multirow{2}{*}{ Strains } & \multirow{2}{*}{ Conidia } & \multicolumn{2}{|c|}{ Size of conidia* } & \multirow{2}{*}{$\%$ of CATs* } & \multicolumn{2}{|c|}{ Germination* $^{*}$} \\
\hline & & Width & Length & & $24 \mathrm{~h}$ & $48 \mathrm{~h}$ \\
\hline \multicolumn{7}{|c|}{ Strains of C. lindemuthianum } \\
\hline LV134 & Cylindric & $3.78 \pm 0.81^{B}$ & $15.24 \pm 2.87^{\mathrm{B}}$ & $28.5 \pm 7.78^{A}$ & $34.5 \pm 4.94^{\mathrm{A}}$ & $75.0 \pm 2.82^{\mathrm{A}}$ \\
\hline LV145 & Cylindric & $3.94 \pm 0.50^{B}$ & $17.47 \pm 2.15^{A}$ & $11.0 \pm 0.00^{B}$ & $2.0 \pm 1.41^{\mathrm{C}}$ & $37.5 \pm 2.12^{C}$ \\
\hline LV153 & Cylindric & $4.13 \pm 0.59^{\mathrm{B}}$ & $16.51 \pm 1.70^{\mathrm{A}}$ & $1.5 \pm 0.71^{\mathrm{C}}$ & $44.0 \pm 5.66^{\mathrm{C}}$ & $75.5 \pm 3.53^{\mathrm{A}}$ \\
\hline LV175 & Cylindric & $4.31 \pm 0.91^{B}$ & $17.09 \pm 2.24^{\mathrm{A}}$ & $3.5 \pm 0.71^{\mathrm{C}}$ & $28.5 \pm 3.53^{B}$ & $53.5 \pm 7.78^{\mathrm{B}}$ \\
\hline LV228 & Cylindric & $5.98 \pm 1.21^{\mathrm{A}}$ & $12.58 \pm 1.61^{\mathrm{C}}$ & $12.5 \pm 2.12^{B}$ & $25.5 \pm 4.95^{\mathrm{B}}$ & $32.0 \pm 4.24^{\mathrm{C}}$ \\
\hline LV238 & Cylindric & $6.09 \pm 1.28^{\mathrm{A}}$ & $17.01 \pm 1.28^{\mathrm{A}}$ & $13.0 \pm 4.24^{\mathrm{B}}$ & $24.0 \pm 5.66^{B}$ & $25.5 \pm 2.12^{C}$ \\
\hline \multicolumn{7}{|c|}{ Strains Colletotrichum spp } \\
\hline G7-2 & Cylindric & $4.78 \pm 0.71^{\mathrm{E}}$ & $15.10 \pm 5.66^{\mathrm{D}}$ & $79.0 \pm 5.66^{A}$ & $30.0 \pm 4.24^{\mathrm{D}}$ & $86.5 \pm 4.94^{\mathrm{A}}$ \\
\hline G8-11 & Falcated & $9.30 \pm 0.87^{A}$ & $22.59 \pm 0.00^{\mathrm{B}}$ & $\mathrm{Nf} \pm 0.00^{\mathrm{E}}$ & $34.5 \pm 4.95^{\mathrm{D}}$ & $75.0 \pm 9.89^{A}$ \\
\hline G15-5 & Cylindric & $2.93 \pm 0.58^{G}$ & $9.05 \pm 7.07^{\mathrm{H}}$ & $14.0 \pm 7.07^{\mathrm{E}}$ & $21.5 \pm 4.95^{\mathrm{E}}$ & $47.5 \pm 6.36^{\mathrm{E}}$ \\
\hline G25-1 & Cylindric & $3.31 \pm 0.73^{\mathrm{G}}$ & $10.54 \pm 8.49^{G}$ & $53.0 \pm 8.49^{\mathrm{C}}$ & $32.0 \pm 5.65^{\mathrm{D}}$ & $82.0 \pm 9.89^{A}$ \\
\hline G43-2 ${ }^{1}$ & Falcated & $7.69 \pm 0.87^{C}$ & $21.84 \pm 0.00^{C}$ & $\mathrm{Nf} \pm 0.00^{\mathrm{E}}$ & $50.5 \pm 4.95^{C}$ & $87.5 \pm 6.36^{A}$ \\
\hline G68-1 & Cylindric & $4.04 \pm 0.60^{F}$ & $15.39 \pm 2.12^{\mathrm{D}}$ & $10.5 \pm 2.12^{\mathrm{E}}$ & $6.0 \pm 4.24^{F}$ & $39.0 \pm 8.48^{F}$ \\
\hline G85-1 & Cylindric & $5.13 \pm 0.60^{\mathrm{E}}$ & $15.07 \pm 9.90^{\mathrm{D}}$ & $67.0 \pm 9.90^{A}$ & $82.5 \pm 10.61^{A}$ & $92.0 \pm 5.66^{\mathrm{A}}$ \\
\hline G86-1 & Cylindric & $4.84 \pm 0.85^{\mathrm{E}}$ & $15.40 \pm 1.41^{\mathrm{D}}$ & $5.0 \pm 1.41^{\mathrm{E}}$ & $79.5 \pm 12.02^{\mathrm{A}}$ & $93.0 \pm 4.24^{\mathrm{A}}$ \\
\hline G89-1 & Cylindric & $4.11 \pm 0.60^{F}$ & $15.21 \pm 5.66^{\mathrm{D}}$ & $10.0 \pm 5.65^{\mathrm{E}}$ & $67.0 \pm 4.24^{B}$ & $86.0 \pm 1.41^{\mathrm{A}}$ \\
\hline G92-1 & Cylindric & $4.20 \pm 0.72^{F}$ & $12.23 \pm 4.24^{F}$ & $20.0 \pm 4.24^{\mathrm{D}}$ & $21.0 \pm 4.24 \mathrm{E}$ & $65.5 \pm 2.12^{\mathrm{C}}$ \\
\hline G93-1 & Cylindric & $4.16 \pm 0.56^{F}$ & $11.00 \pm 0.71^{\mathrm{G}}$ & $8.5 \pm 0.71^{\mathrm{E}}$ & $44.5 \pm 4.95^{\mathrm{C}}$ & $68.0 \pm 1.41^{\mathrm{C}}$ \\
\hline G99-1 & Cylindric & $4.87 \pm 0.73^{\mathrm{E}}$ & $15.81 \pm 11.3^{\mathrm{D}}$ & $47.0 \pm 11.31^{\mathrm{C}}$ & $47.0 \pm 8.48^{C}$ & $88.0 \pm 5.66^{A}$ \\
\hline S1 & Falcated & $4.81 \pm 0.99^{\mathrm{E}}$ & $28.94 \pm 4.24^{\mathrm{A}}$ & $\mathrm{Nf} \pm 0.00^{\mathrm{E}}$ & $54.5 \pm 3.53^{C}$ & $90.5 \pm 2.12^{A}$ \\
\hline S2 & Cylindric & $6.25 \pm 1.54^{\mathrm{D}}$ & $13.91 \pm 3.54^{\mathrm{E}}$ & $22.5 \pm 3.54^{\mathrm{D}}$ & $17.5 \pm 3.53^{\mathrm{E}}$ & $26.5 \pm 3.53^{\mathrm{G}}$ \\
\hline S5 & Cylindric & $6.45 \pm 1.07^{D}$ & $14.12 \pm 3.54^{\mathrm{E}}$ & $27.5 \pm 3.54^{\mathrm{D}}$ & $37.5 \pm 4.95^{\mathrm{D}}$ & $60.0 \pm 4.24^{D}$ \\
\hline S6 & Cylindric & $8.26 \pm 1.86^{B}$ & $14.13 \pm 1.41^{\mathrm{E}}$ & $83.0 \pm 1.41^{\mathrm{A}}$ & $49.0 \pm 4.24^{\mathrm{C}}$ & $92.0 \pm 1.41^{\mathrm{A}}$ \\
\hline
\end{tabular}

*Means followed by the same letter belong the same group $(P<0.05)$ according to the Scott-Knott test. ${ }^{1}$ Evaluation of ascospores. CATs $=$ conidial anastomosis tubes.
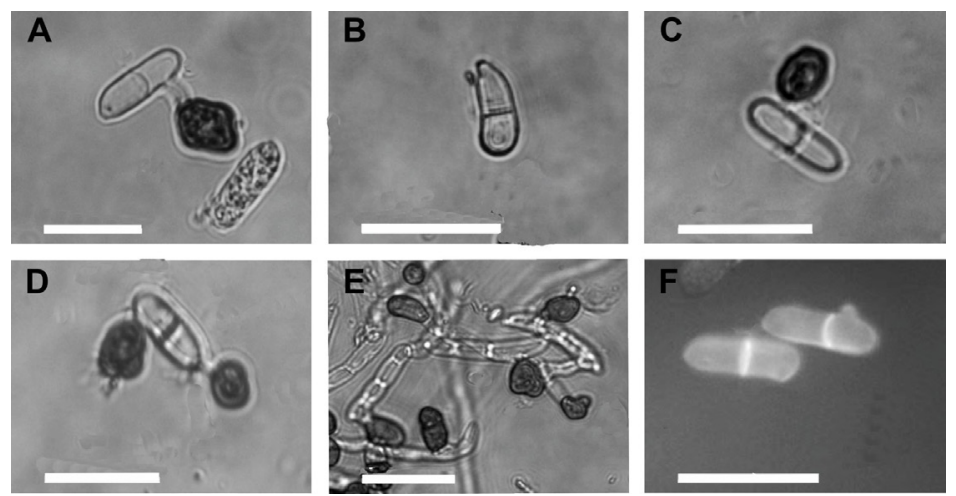

Figure 3. Septated conidia germination. A. Strain G85-1. B. Strain LV228. C. Strain S6. D. Strain S5. E. Strain S1. F. Strain G7-2. A-E. Light microscopy and stained with calcofluor. F. Interference contrast microscopy. Scale A-F $=20 \mu \mathrm{m}$. 


\section{Conidial anastomosis tubes}

All of the strains in the $C$. lindemuthianum group exhibited CATs and formed three distinct groups. The fusion percentage ranged from 1.5\% (LV153) to 28.5\% (LV134). For the group of others, the strains were classified into five distinct groups and the fusion percentage ranged from 0\% (G8-1, G43-2, and S1) to 83\% of CATs for the S6 strain (Figure 4 and Table 4).
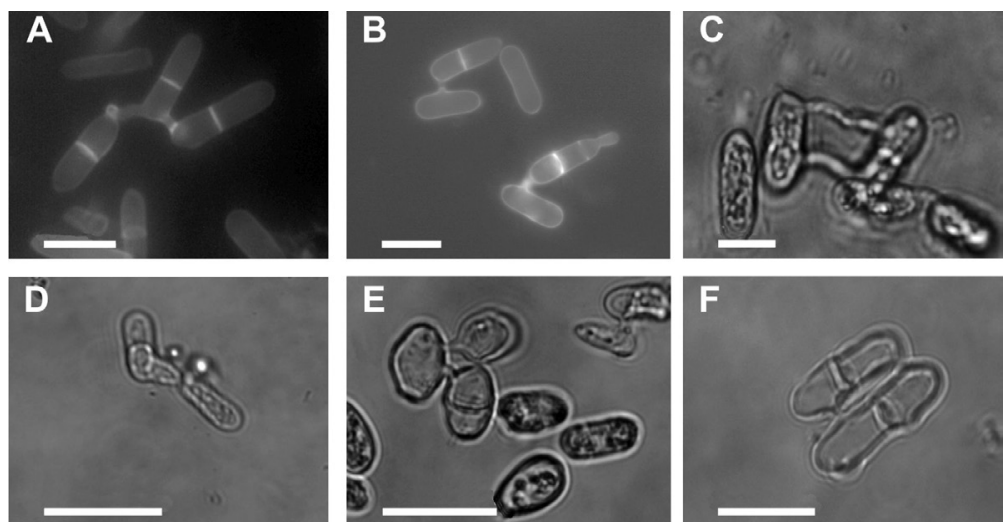

Figure 4. Formation of conidial anastomosis tubes A. Strain G68-1. B. Strain G7-2. C. Strain S6. D. Strain LV228. E. Strain S2. F. Strain G92-1. A and B. Light microscopy stained with calcofluor. C, D, E, and F. Interference contrast microscopy. Scale A-F $=10 \mu \mathrm{m}$.

\section{Pathogenicity test}

The races of the $C$. lindemuthianum strains and the pathogenicity of Glomerella spp strains (group I) were previously obtained in the study of Barcelos et al. (2014), Table 1. Strains of the Glomerella spp II groups were also inoculated in a study by Barcelos et al. (2014) and caused mild symptoms when evaluated at 10 days. Nevertheless, pathogenicity tests were once more carried out for strains of the Glomerella spp II group and for the Colletotrichum spp strains. The cultivar $x$ strain interaction was significant for disease severity. Therefore, mean tests were carried out to compare the response of each cultivar to the different strains at 17 days. At 17 days, the means obtained were similar for the different strains. For most of the cultivars, the strains were classified in two groups, except for the cultivars Majestoso of common bean and CD237 of soybean, which exhibited three groups (Table 5). Nevertheless, there was no separation between strains derived from the anthracnose lesion and those derived from scab lesions. The numbers of strains within each group varied by cultivar (Table 6).

The strain $x$ day interaction was also significant $(P<0.05)$, i.e., the behavior of the strains differed in the different periods of evaluation of severity. The symptoms observed at 7 days after inoculation were similar among the strains evaluated (Table 6). Two groups were formed following evaluation at 10 and 14 days after inoculation; however, there was no separation between strains derived from the anthracnose lesion and those derived from scab lesions. Moreover, the number of lines within each group varied according to the period of evaluation and the strains belonging to each group (Table 6). At 17 days, the strains were classified into four groups according to the evaluation of disease severity, with scores ranging from 2.210 (G92-1) to 3.832 (G86-1). 
Table 5. Average score disease severity of each cultivar inoculated with each Colletotrichum strain in evaluation at 17 days.

\begin{tabular}{l|c|c|c|c|c|c}
\hline \multirow{2}{*}{ Strains } & \multicolumn{5}{|c}{ Cultivar $^{*}$} \\
\cline { 2 - 6 } & Pérola & Majestoso & Talismã & CD237 & Favorita & CD202 \\
\hline G85-1 & $1.95 \pm 0.45^{\mathrm{B}}$ & $2.67 \pm 0.86^{\mathrm{A}}$ & $4.89 \pm 1.15^{\mathrm{B}}$ & $2.82 \pm 0.91^{\mathrm{A}}$ & $2.25 \pm 0.75^{\mathrm{A}}$ & $3.15 \pm 0.50^{\mathrm{A}}$ \\
\hline G86-1 & $3.72 \pm 0.95^{\mathrm{A}}$ & $4.14 \pm 1.07^{\mathrm{A}}$ & $5.43 \pm 2.02^{\mathrm{A}}$ & $2.95 \pm 1.02^{\mathrm{A}}$ & $3.12 \pm 0.93^{\mathrm{A}}$ & $3.35 \pm 0.77^{\mathrm{A}}$ \\
\hline G89-1 & $2.87 \pm 0.71^{\mathrm{B}}$ & $4.44 \pm 0.88^{\mathrm{A}}$ & $2.92 \pm 0.56^{\mathrm{B}}$ & $2.69 \pm 1.08^{\mathrm{A}}$ & $2.84 \pm 0.64^{\mathrm{A}}$ & $3.50 \pm 0.96^{\mathrm{A}}$ \\
\hline G92-1 & $2.77 \pm 0.72^{\mathrm{B}}$ & $2.79 \pm 0.72^{\mathrm{A}}$ & $2.63 \pm 0.62^{\mathrm{B}}$ & $1.39 \pm 0.23^{\mathrm{A}}$ & $2.13 \pm 0.57^{\mathrm{A}}$ & $1.56 \pm 0.40^{\mathrm{A}}$ \\
\hline G93-1 & $4.17 \pm 1.07^{\mathrm{A}}$ & $3.37 \pm 0.88^{\mathrm{A}}$ & $4.11 \pm 1.05^{\mathrm{A}}$ & $2.97 \pm 0.74^{\mathrm{A}}$ & $1.97 \pm 0.37^{\mathrm{A}}$ & $2.04 \pm 0.62^{\mathrm{A}}$ \\
\hline G99-1 & $3.34 \pm 0.76^{\mathrm{A}}$ & $3.60 \pm 0.96^{\mathrm{A}}$ & $3.78 \pm 0.92^{\mathrm{A}}$ & $3.97 \pm 1.21^{\mathrm{A}}$ & $3.80 \pm 1.31^{\mathrm{A}}$ & $3.90 \pm 1.21^{\mathrm{A}}$ \\
\hline S1 & $1.90 \pm 0.64^{\mathrm{B}}$ & $2.18 \pm 0.54^{\mathrm{A}}$ & $2.51 \pm 0.59^{\mathrm{B}}$ & $2.38 \pm 0.74^{\mathrm{A}}$ & $1.84 \pm 0.38^{\mathrm{A}}$ & $2.60 \pm 0.57^{\mathrm{A}}$ \\
\hline S2 & $2.80 \pm 0.81^{\mathrm{B}}$ & $3.05 \pm 0.91^{\mathrm{A}}$ & $3.67 \pm 1.18^{\mathrm{A}}$ & $2.70 \pm 0.57^{\mathrm{A}}$ & $2.11 \pm 0.52^{\mathrm{A}}$ & $2.00 \pm 0.41^{\mathrm{A}}$ \\
\hline S5 & $2.93 \pm 0.84^{\mathrm{B}}$ & $3.12 \pm 0.90^{\mathrm{A}}$ & $3.44 \pm 0.86^{\mathrm{B}}$ & $2.15 \pm 0.40^{\mathrm{A}}$ & $2.25 \pm 0.42^{\mathrm{A}}$ & $2.06 \pm 0.82^{\mathrm{A}}$ \\
\hline S6 & $4.22 \pm 1.26^{\mathrm{A}}$ & $3.78 \pm 1.05^{\mathrm{A}}$ & $3.92 \pm 0.99^{\mathrm{B}}$ & $2.86 \pm 0.81^{\mathrm{A}}$ & $2.06 \pm 0.48^{\mathrm{A}}$ & $2.60 \pm 0.62^{\mathrm{A}}$ \\
\hline
\end{tabular}

*Means followed by the same letter in column belong the same group $(P<0.05)$ according to the Scott-Knott test.

Table 6. Average score of disease severity of cultivars inoculated with each Colletotrichum strain evaluated at 7 , 10,14 , and 17 days.

\begin{tabular}{l|c|c|c|c}
\hline \multirow{2}{*}{ Strains } & \multicolumn{4}{|c}{ Days } \\
\cline { 2 - 5 } & 7 & 10 & 14 & 17 \\
\hline G85-1 & $1.904 \pm 0.77^{\mathrm{A} 1 \mathrm{~b}}$ & $2.331 \pm 0.91^{\mathrm{Aa}}$ & $2.454 \pm 0.87^{\mathrm{Aa}}$ & $2.454 \pm 0.87^{\mathrm{Da}}$ \\
\hline G86-1 & $1.516 \pm 0.40^{\mathrm{Ad} 2}$ & $2.089 \pm 0.54^{\mathrm{Ac}}$ & $2.810 \pm 1.27^{\mathrm{Ab}}$ & $3.832 \pm 1.21^{\mathrm{Aa}}$ \\
\hline G89-1 & $1.699 \pm 0.71^{\mathrm{AC}}$ & $2.334 \pm 0.71^{\mathrm{Ab}}$ & $2.739 \pm 0.78^{\mathrm{Aa}}$ & $3.157 \pm 0.78^{\mathrm{Ba}}$ \\
\hline G92-1 & $1.242 \pm 0.23^{\mathrm{Ab}}$ & $1.445 \pm 0.38^{\mathrm{Bb}}$ & $2.037 \pm 0.76^{\mathrm{Ba}}$ & $2.210 \pm 0.71^{\mathrm{Da}}$ \\
\hline G93-1 & $1.486 \pm 0.52^{\mathrm{Ad}}$ & $1.963 \pm 0.56^{\mathrm{Ac}}$ & $2.482 \pm 0.98^{\mathrm{Ab}}$ & $3.202 \pm 0.97^{\mathrm{Ba}}$ \\
\hline G99-1 & $1.426 \pm 0.38^{\mathrm{Ad}}$ & $1.882 \pm 0.56^{\mathrm{BC}}$ & $2.782 \pm 0.62^{\mathrm{Ab}}$ & $3.730 \pm 0.58^{\mathrm{Aa}}$ \\
\hline S1 & $1.263 \pm 0.39^{\mathrm{Ab}}$ & $1.784 \pm 0.60^{\mathrm{Ba}}$ & $2.141 \pm 0.52^{\mathrm{Ba}}$ & $2.265 \pm 0.56^{\mathrm{Da}}$ \\
\hline S2 & $1.172 \pm 0.19^{\mathrm{AC}}$ & $1.662 \pm 0.28^{\mathrm{Bb}}$ & $2.461 \pm 0.57^{\mathrm{Aa}}$ & $2.764 \pm 0.69^{\mathrm{Ca}}$ \\
\hline S5 & $1.463 \pm 0.31^{\mathrm{Ab}}$ & $1.645 \pm 0.28^{\mathrm{Bb}}$ & $2.510 \pm 0.58^{\mathrm{Aa}}$ & $2.750 \pm 0.66^{\mathrm{Ca}}$ \\
\hline S6 & $1.405 \pm 0.29^{\mathrm{Ad}}$ & $1.887 \pm 0.40^{\mathrm{Bc}}$ & $2.521 \pm 0.46^{\mathrm{Ab}}$ & $3.239 \pm 1.05^{\mathrm{Ba}}$ \\
\hline
\end{tabular}

*Means followed by the same uppercase letter in the column or the same lowercase letter in the row belong the same group $(P<0.05)$ according to the Scott-Knott test. ${ }^{1}$ Comparasion of means among Colletotrichum strains within each day. ${ }^{2}$ Comparison of mean behavior of each Colletotrichum strain in different days.

These results showed there was disease progression in cultivars, for all of the strains evaluated; therefore, the symptoms were more severe during this period of evaluation. Symptoms in stems and leaves of soybean and common bean cultivars caused by strains derived from anthracnose and scab lesions may be observed in Figures 5 to 8 . Symptoms observed in stems and leaves of soybean plants following inoculation were typical of anthracnose in this species, but the symptoms observed in the same plant tissues of common bean are similar to those typical of anthracnose and scab in this species. These results may be observed in the field; i.e., in the stem and leaves, the symptoms are mixed together, and on the pod, simultaneous occurrence of the two diseases may 
be observed (Figure 9). Evaluation of the pods of the common bean cultivar Talismã at the end of the cycle revealed symptoms typical of common bean scab for all strains evaluated (Figure 10). Nevertheless, the intensity of the symptoms varied.
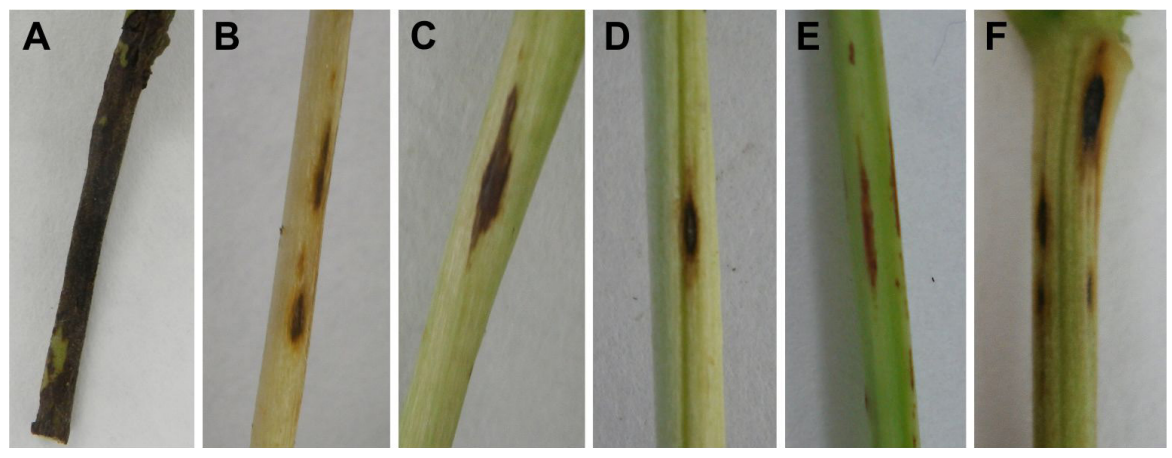

Figure 5. Symptoms caused by Colletotrichum on bean stalks 17 days after inoculation on the cultivar Majestoso. A. Strain LV238. B. Strain G86-1. C. Strain G89-1. D. Strain S5. E. Strain G99-1. F. Strain S2.
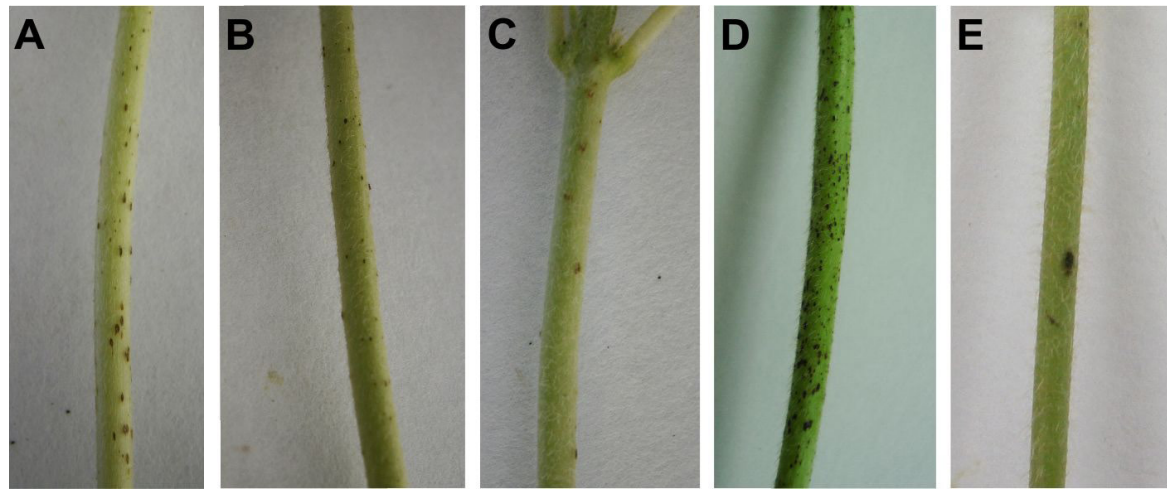

Figure 6. Symptoms caused by Colletotrichum on bean leaves 17 days after inoculation on the cultivar Majestoso. A. Strain LV238. B. Strain S1. C. Strain G92-1. D. Strain G93-1. E. Strain G99-1. F. Strain S2. G. Strain S5. H. Strain S6.
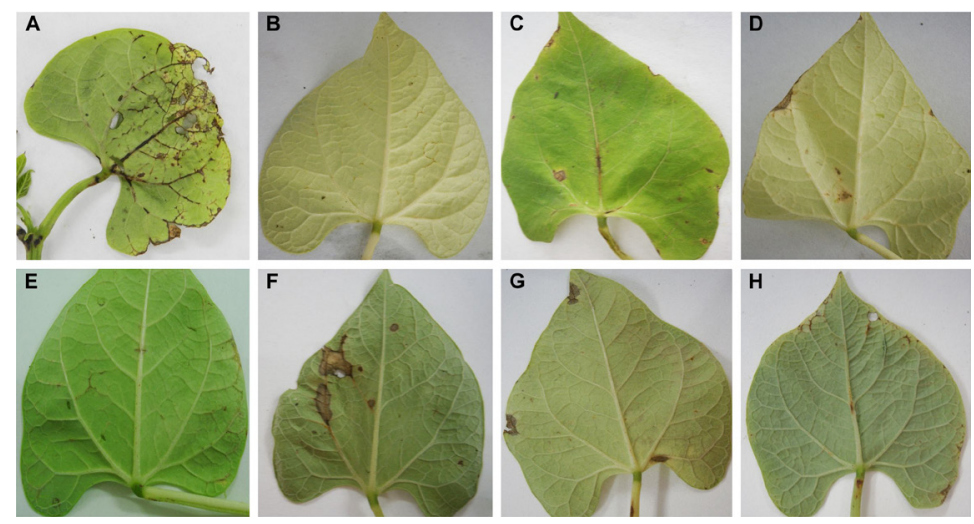

Figure 7. Symptoms of the disease caused by Colletotrichum on the stems of soybean 17 days after inoculation on cultivar CD237. A. Strain G86-1. B. Strain G89-1. C. Strain G92-1. D. Strain G99-1. E. Strain S6. 

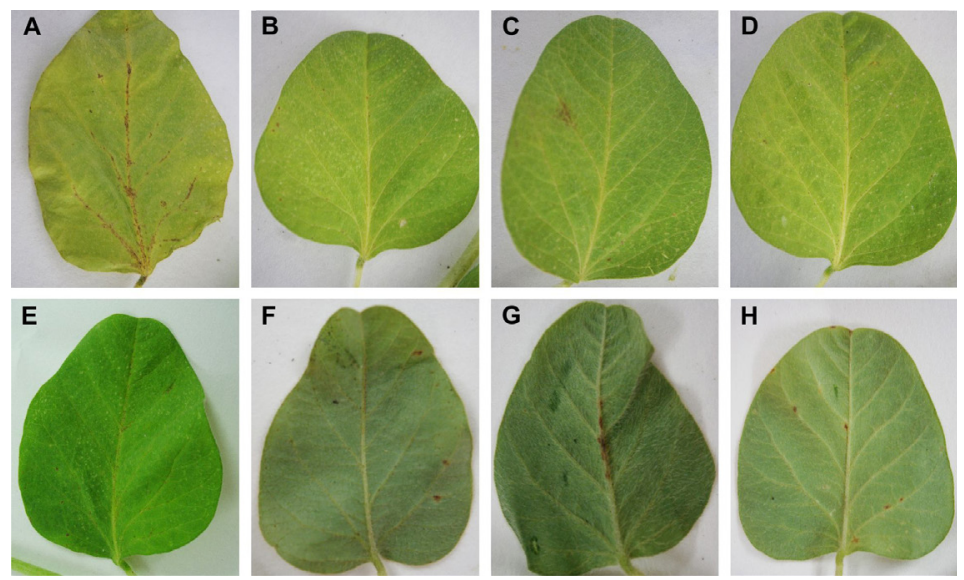

Figure 8. Symptoms caused by Colletotrichum on soybean leaves 17 days after inoculation on the cultivar CD237. A. Strain G85-1. B. Strain G86-1. C. Strain 89-1. D. Strain G93-1. E. Strain G99-1. F. Strain S1. G. Strain S2. H. Strain S6.
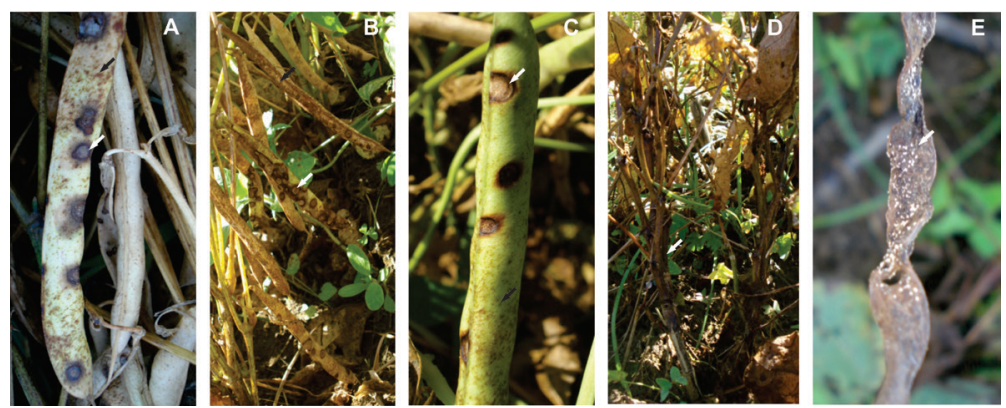

Figure 9. Common bean plants infected naturally. A., B. and C. Pod with symptoms of scabies and anthracnose. The white arrow represents anthracnose (rounded lesions) and the black arrow represents scabies. D. Stems infected with the disease, unable to distinguish between anthracnose and scabies. E. Pod with symptom of scabies and presence of acervula indicated by the arrow.
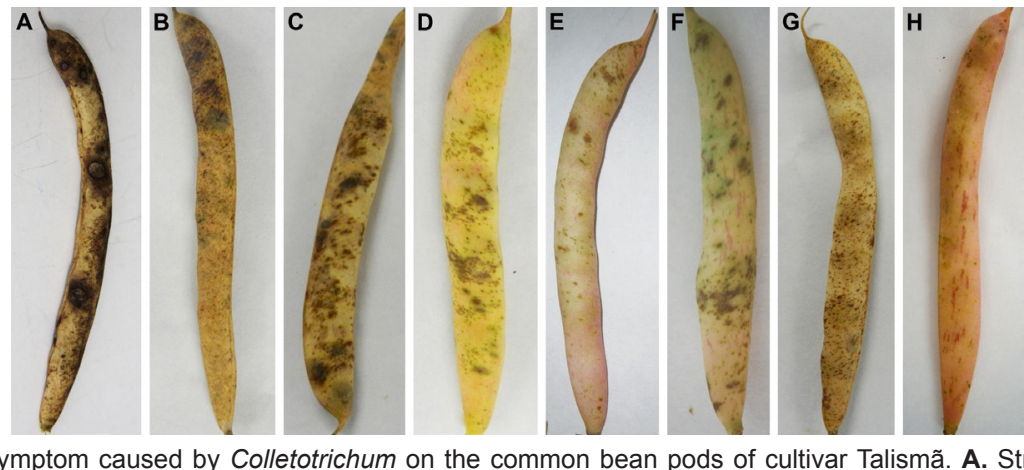

Figure 10. Symptom caused by Colletotrichum on the common bean pods of cultivar Talismã. A. Strain LV238. B. Strain G85-1. C. Strain G86-1. D. Strain G89-1. E. Strain G92-1. F. Strain 93-1. G. Strain S6. H. Strain S1. 


\section{Amplification of the HMG region of the mating-type gene}

The HMG region of the mating-type gene MAT1-2-1 only amplified in strains of the C. lindemuthianum group (García-Serrano et al., 2008). When primer pairs specific for the HMG region of the mating-type gene MAT1-2-1 were tested (Barcelos et al., 2011), the expected product amplified only in G7-2, G8-1, G15-5, G25-1, G43-2, and G68-1. However, amplified product was observed from all strains when evaluated with the primer pairs specific for Glomerella truncata, CT21HMGF, and CT21HMGR (Menat et al., 2012).

\section{Amplification with the IRAP marker}

Two pairs of primers tested exhibited polymorphism, amplifying a total of 49 polymorphic bands; 24 polymorphic bands for the primer pair IRAP1/IRAP4, and 25 for IRAP2/IRAP4 (Figure 11). Based on the 49 polymorphic bands, a similarity matrix was constructed and estimates of genetic similarities were obtained, which ranged from 0.217 to 1.0. Dendrogram was obtained, and the cutoff line given by the sgm estimate was 0.75037 . It was possible to observe the formation of 14 similarity groups (Figure 12).

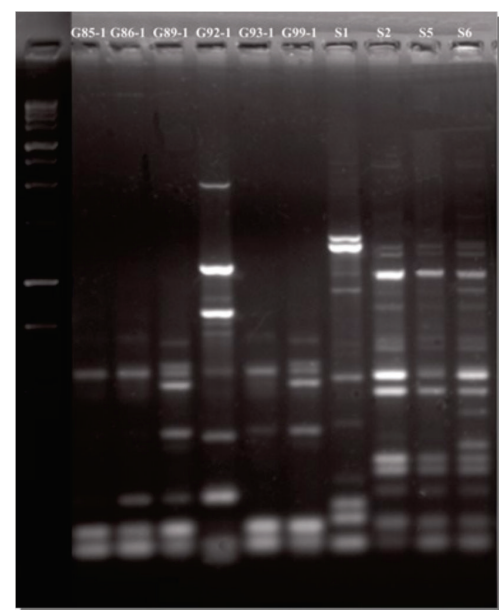

Figure 11. Polymorphic bands generated by amplification with the primer pair IRAP2/IRAP4, specific for the strains of scabies that caused the disease.

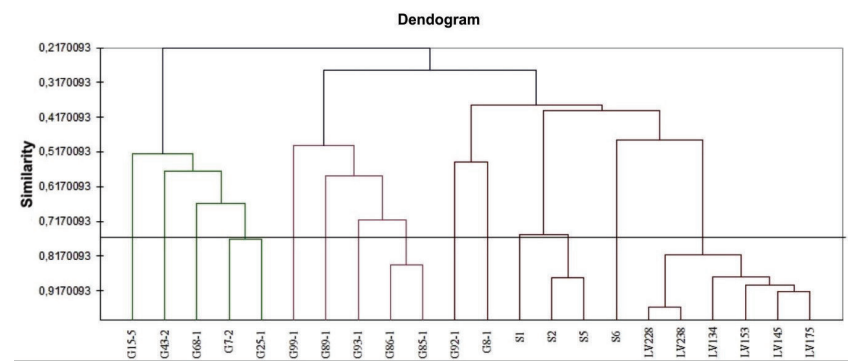

Figure 12. Dendrogram of genetic similarity using inter-retrotransposon amplified polymorphism (IRAP) markers in 22 Colletotrichum strains. 
To confirm pathogenicity (i.e., to confirm that the symptoms observed were caused by the inoculated strains), lesions of the leaves, stems, and pods of the different cultivars were newly isolated for all of the strains inoculated. After new isolations were made, the DNA was extracted from both strains used in the inoculation and those obtained from the new isolations were subjected to IRAP marker analysis. Amplicons were evaluated and the same pattern of bands was obtained from the inoculated strains as was obtained from new isolations (data not shown).

\section{Sexual and mycelial compatibility}

The numbers of compatible reactions for each strain were estimated to analyze mycelial compatibility (Table 7), and the strain G86-1 was found to exhibit $31.82 \%$ compatibility with the other strains. However, some strains did not exhibit compatibility. Similarity, estimates ranged from 0 to 0.27 and the cutoff line $(\mathrm{sgm})$ was 0.95 . From the dendrogram obtained by cluster analysis, 22 different groups were formed; i.e., each line was represented by a distinct group. Among the pairs of strains that exhibited mycelial compatibility, five pairs formed perithecia with asci and ascospores at the line of contact between the colonies: G92-1/S2; S2/S5, S2/S6, S6/S5, and G8-1/G7-2 (Figure 13).

\begin{tabular}{|c|c|c|c|c|c|c|c|c|c|c|c|c|c|c|c|c|c|c|c|c|c|c|c|}
\hline Strains & $A^{*}$ & B & C & D & $\mathrm{E}$ & $\mathrm{F}$ & G & $\mathrm{H}$ & 1 & $\mathrm{~J}$ & K & L & M & $\mathrm{N}$ & 0 & P & Q & $\mathrm{R}$ & S & $\mathrm{T}$ & U & V & $\%$ \\
\hline A & - & + & + & - & - & - & - & - & - & - & - & - & - & - & - & - & - & - & - & - & - & - & 9.09 \\
\hline B & & + & + & - & + & + & - & - & + & + & - & - & + & - & - & - & - & - & - & - & - & - & 31.82 \\
\hline C & & & + & - & + & + & - & - & - & - & - & - & + & - & - & - & - & - & - & - & - & - & 27.27 \\
\hline $\mathrm{D}$ & & & & - & - & - & - & + & - & - & - & - & + & - & - & - & - & - & - & - & - & - & 9.09 \\
\hline$E$ & & & & & + & + & - & - & - & - & - & - & - & - & - & - & - & - & - & - & - & - & 18.18 \\
\hline $\mathrm{F}$ & & & & & & + & + & - & + & + & - & - & - & - & - & - & - & - & - & - & - & - & 27.27 \\
\hline G & & & & & & & - & - & + & - & - & - & - & - & - & - & - & - & - & - & - & - & 4.55 \\
\hline $\mathrm{H}$ & & & & & & & & - & + & + & - & - & - & - & - & - & - & - & - & - & - & - & 13.64 \\
\hline 1 & & & & & & & & & - & + & - & - & - & - & - & - & - & - & - & - & - & - & 22.73 \\
\hline $\mathrm{J}$ & & & & & & & & & & - & - & - & - & - & - & + & - & - & - & - & - & - & 22.73 \\
\hline $\mathrm{K}$ & & & & & & & & & & & - & + & - & - & - & - & - & - & - & - & - & - & 4.55 \\
\hline $\mathrm{L}$ & & & & & & & & & & & & - & - & - & - & - & - & - & - & - & - & - & 4.55 \\
\hline M & & & & & & & & & & & & & - & - & - & - & - & - & - & - & - & - & 13.64 \\
\hline $\mathrm{N}$ & & & & & & & & & & & & & & - & - & - & - & - & - & - & - & - & 0 \\
\hline 0 & & & & & & & & & & & & & & & - & - & - & - & - & - & - & - & 0 \\
\hline$P$ & & & & & & & & & & & & & & & & - & - & - & - & - & - & - & 0 \\
\hline Q & & & & & & & & & & & & & & & & & - & - & - & - & - & - & 0 \\
\hline$\underline{R}$ & & & & & & & & & & & & & & & & & & - & - & - & - & - & 0 \\
\hline$\underline{s}$ & & & & & & & & & & & & & & & & & & & - & - & - & - & 0 \\
\hline $\mathrm{T}$ & & & & & & & & & & & & & & & & & & & & - & - & - & 0 \\
\hline$\underline{U}$ & & & & & & & & & & & & & & & & & & & & & - & - & 0 \\
\hline V & & & & & & & & & & & & & & & & & & & & & & - & 0 \\
\hline
\end{tabular}

*A. G85; B. G-86; C. G89; D. G92; E. G93; F. G99; G. S1; H. S2; I. S5; J. S6; K. G7-2; L. G8-1; M. G15-5; N. G25-1; O. G43-2; P. G68-1; Q. LV134; R. LV145; S. LV153; T. LV-175; U. LV282; V. LV238. + compatible; - incompatible. 

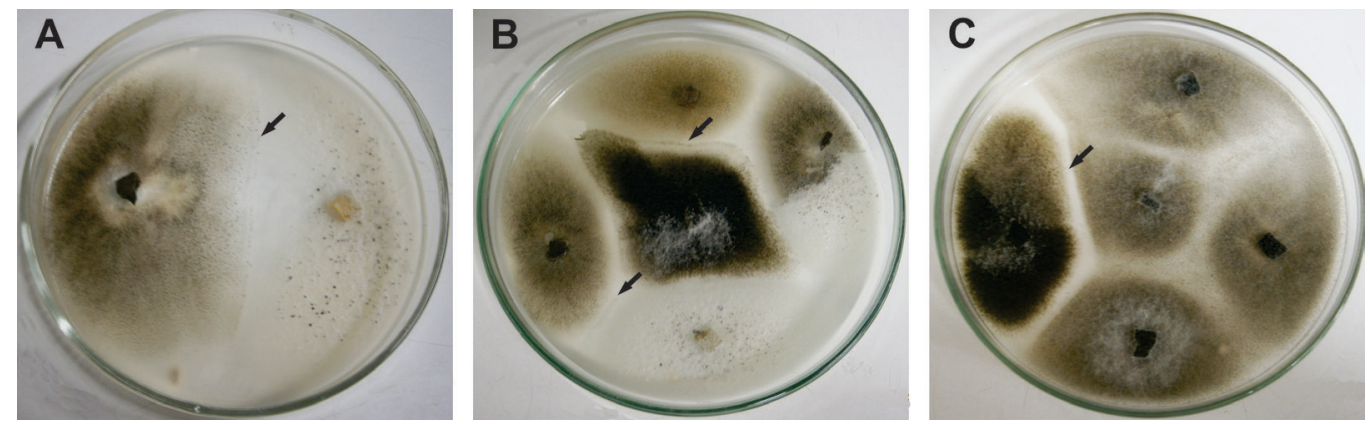

Figure 13. Plates of pairings showing the contact line and the formation of perithecia. A. Compatibility between strain S2 with white strain S5. B. Compatibility line between the central strains S2 and strains G92-1 and between the strain S2 and strain S5 again. In the figures, arrows A and B indicate the formation of lines with perithecia. C. Micelial incompatibility (arrow) between strain G89-1 (central) and strain G92-1 (left).

\section{DISCUSSION}

In a recent study, strains of $C$. lindemuthianum and Glomerella spp were obtained from anthracnose lesions in common bean (Barcelos et al., 2014). Comparative analyses of morphological and molecular traits, as well as pathogenicity tests of these strains, have revealed great variability and indicated that strains of Glomerella sp do not represent the teleomorphic form of $C$. lindemuthianu. In the same study, two distinct groups of Glomerella sp strains collected from anthracnose lesions in common bean were identified and named Glomerella sp groups I and II. Based on data obtained from molecular markers, pathogenicity tests, and sporulation in common bean pods, the primers HMGglo were observed to amplify bands in the Glomerella sp I group whereas no amplification was observed when primers specific to $C$. lindemuthianum were used (García-Serrano et al., 2008). In addition, these do not cause symptoms in common bean or sporulation in the M3 medium, A group of six strains named Glomerella sp II did not amplify for both primers, caused mild symptoms in common bean, and sporulated in sterilized common bean pods. Due to the simultaneous occurrence of scab and anthracnose symptoms, and the similarity of these symptoms in common bean plants in the field, this study performed a comparative analysis between strains of C. lindemuthianum and strains of Glomerella sp II (Barcelos et al., 2014) collected from anthracnose lesions in common bean and strains of Colletotrichum spp derived from common bean scab lesions. Moreover, we compared the pathogenicity of strains in the Glomerella sp II group and scab in common bean and soybean plants.

Great variability was observed for all traits evaluated between and within the groups of strains analyzed. Significant differences were observed in relation to IMGR and colony diameter $(P<0.05)$. For the $C$. lindemuthianum group, this variability has been previously reported (Souza et al., 2007; Pinto et al., 2012; Liu et al., 2013). Differences between the mean IMGR of the $C$. lindemuthianum group $(2.56 \mathrm{~mm} / \mathrm{day})$ and of the group of others $(10.07 \mathrm{~mm} / \mathrm{day})$ were highly discrepant; this was also observed by Barcelos et al. (2014) when strains of Glomerella sp I and II were evaluated. It is noteworthy that in spite of the formation of different groups by the mean test involving the strains of anthracnose and scab lesions, there was not a clear separation between the strains originating from the lesions of the two diseases. For the $C$. lindemuthianum group, evaluation of colony diameter was carried out at 15 days from the beginning of the experiment, while in the group of others, this was performed after 8 days of growth because $50 \%$ of the strains 
had already reached the maximum diameter of the Petri dish. There are reports in the literature of $C$. truncatum strains derived from lentil, soybean, and peanut crops, among others, growing between 2 and $8.6 \mathrm{~mm} /$ day (Damm et al., 2009).

Analysis of morphological traits is useful in the characterization of different strains of a species, and can assist in genetic analyses when contrasting strains are identified for each trait, and also for the differentiation of a genus (Souza et al., 2007). In strains of the $C$. lindemuthianum group, the conidia exhibited variation in length $(12.58-17.47 \mu \mathrm{m})$ and width $(3.78-6.09 \mu \mathrm{m})$. These values are in agreement with other data described in the literature for these species (Roca et al., 2003; Pinto et al., 2012; Liu et al., 2013). For the strains belonging to the group of others, S1 exhibited a steadily narrower curved format toward the extremities and a size of $24.94 \times 4.81 \mu \mathrm{m}$. These values are in agreement with data described in the literature for the species $C$. truncatum derived from different hosts (Damm et al., 2009). The size of the ascopores of the strains G43-2 (21.84 x $7.69 \mu \mathrm{m})$ and G8-1 $(22.59 \times 9.3 \mu \mathrm{m})$ is in agreement with the data described previously in the literature for the species G. cingulata f. spp phaseoli (Castro et al., 2006; Souza et al., 2007); however, these values are higher than those reported by Kimati and Galli (1970) and Rodrigues-Guerra et al. (2005).

Physiological traits may directly assist in classification of strains that can establish themselves on the surface of a host with greater ease, i.e., they are important for understanding the events of preand post-infection of the host by the pathogen (Barcelos et al., 2014). In the present study, high levels of diversity were detected through the analysis of conidia and ascopore germination in the group of others and conidia of the $C$. lindemuthiahum group, including between the two time evaluated (24 and $48 \mathrm{~h}$ ), for both groups. The mean germination for both time points was greater in the group of others, which has previously been reported (Barcelos et al., 2014) for the Glomerella sp I and II strains derived from anthracnose. The sporulation rate of a pathogen affects its dispersion capacity, which subsequently affects the spatial distribution of the species (Pereira et al., 2006). Moreover, it is reported that $C$. lindemuthianum has limited dispersion capacity, which occurs preferentially between different parts of the same plant and occasionally between adjacent plants (Souza et al., 2010). The $C$. lindemuthianum group exhibited low sporulation in solid M3 medium, which is used as a standard for the evaluation of all groups; however, conditions that can be used for the sporulation of $C$. lindemuthianum have been described, and include the use of M3S medium and inoculation on sterile common bean pods (Talamini et al., 2004). For both groups, the optimal sporulation time was 16 days, and the strains obtained from scab lesions exhibited a greater rate of sporulation.

The absence of septa during the germination of conidia for $C$. lindemuthianum has been previously reported, and this phenotype is considered for differentiation of the species in this genus (Bailey and Jeger, 1992; Liu et al., 2013). Nevertheless, septa have been reported in C. lindemuthianum populations (Pinto et al., 2012). In the present study, all strains of $C$. lindemuthianum exhibited variable percentages of septum formation in germinated conidia. The S1 strain derived from the scab lesion (Colletotrichum spp group) formed a septum, consistent with the reported literature for $C$. truncatum (Damm et al., 2009).

Colletotrichum (and its teleomorph Glomerella) is a genus that has diverse life styles, which range from necrotrophic to latent pathogens, and may also be epiphytes (Hyde et al., 2009). Colletotrichum is a common epiphytic inhabitant of leaf tissue, where they may persist as spores, appressoria, or mycelia (Latunde-Dada et al., 1999). Thus, in Colletotrichum, the relationship between pathogenicity, endophytism, epiphytism, and saprophytism is not clear, and some species seem to have more than one life style (Oliveira, 1991). In a study by Barcelos et al. (2014), this relationship was identified for strains derived from anthracnose lesions, in which the Glomerella sp I group obtained epiphytic behavior, while Glomerella sp II caused mild symptoms in common bean. 
Six strains G85-1, G86-1, G89-1, G92-1, G93-1, and G99-1 (Glomerella sp II), which were obtained from anthracnose lesions, have been previously analyzed with regards to pathogenicity and resulted in mild disease symptoms (Barcelos et al., 2014). In the present study, these strains, and S1, S2, S5, and S6 (Colletotrichum spp group) derived from scab lesions, were inoculated on adapted common bean and soybean cultivars. These strains caused symptoms on the leaves and stems of common bean that were similar to those of anthracnose and scab, i.e., as the disease developed, the tissue became necrotic and showed a brown color. These lesions grow longitudinally on the stem, increase in size, and can take up the entire diameter (Mota et al., 2015). Nevertheless, the symptoms observed on the soybean cultivars were similar to those of anthracnose. When the common bean pods were evaluated, the lesions were typical of those in scab. Two diseases may occur simultaneously in common bean plants in the field, and it is not possible to clearly distinguish the symptoms on stems and leaves (Figure 9). Nevertheless, on the pods, the symptoms are easily distinguishable (Figure 10). Symptoms caused by the Glomerella sp II strains and Colletotrichum spp strains manifested late in comparison to those of $C$. lindemuthianum, which cause anthracnose in common bean. These results show that different species of Colletotrichum co-inhabit lesions, and a similar situation was reported in cowpea beans by Latunde-Dada et al. (1999), where more than one species of Colletotrichum was observed in anthracnose lesions. Recently, strains of $C$. lindemuthianum and Glomerella sp have been obtained from anthracnose lesions where the strains of Glomerella sp I survive as epiphytes and opportunists, forming mycelia and appressoria on the surface of tissues, and may develop hyphae in anthracnose lesions (Barcelos et al., 2014). Strains of both the Glomerella sp II and the Colletotrichum spp groups caused anthracnose symptoms in soybean cultivars. However, only one of the Colletotrichum spp strains exhibited conidia that were slightly curved and narrower at the extremities, similar to $C$. truncatum, which is reported as the causal agent of anthracnose in soybean.

Among the mechanisms that may assist in generation of the variability shown for the traits analyzed in this study, the following stand out: sexual recombination (Souza et al., 2010), the parasexual cycle (Castro-Prado et al., 2007), and asexual recombination through fusion of CATs (Roca et al., 2003; Ishikawa et al., 2012). Regarding the sexual recombination of strains, only $11.69 \%$ of the combinations exhibited sexual compatibility, whereas $0 \%$ of $C$. lindemuthianum strains were compatible. Of the compatible combinations, only five combinations exhibited production of asci and ascospores. Studies on the sexual phase of the Colletotrichum genus indicate that genetic control of reproduction in this pathogen does not correspond to a simple-mating system, and that more than one locus in the genome is likely to be involved in this control (Bailey and Jeger, 1992; Barcelos et al., 2014). We observed perithecia formation on the contact line, but we cannot say that sexual reproduction has occurred between these strains. Perithecia may be produced by the induction of molecules in one strain being produced by the other strain used in pairing, due to the activation of some previously blocked metabolic route (Weber and Webster, 1998). Compatibility was observed between two strains, G92-1 and S2, derived from anthracnose and scab lesions, respectively (Glomerella sp II and Colletotrichum spp). However, when strains were grouped, each strain gave rise to a different group, and were therefore, not similar.

An alternative method of asexual recombination between vegetative incompatible strains was suggested by Ishikawa et al. (2012) through the formation of CATs. In the present study, the fusion of CATs was common in most of the strains (90.9\%). Considering that CATs play an important role in the population dynamics of phytopathogens, a high frequency may significantly affect variability of the pathogen in the populations analyzed. In this study, we observed that six strains exhibited a proportion of CAT formation greater than $25 \%$, and among these are strains of 
the C. lindemuthianum group (LV134), the Glomerella sp II and Colletotrichum spp (G85-1, G99-1, and S6) groups, and also strains that were not pathogenic (G7-2 and G25-1). Among these strains, G85-1, S6, G7-2, and G25-1 exhibited percentages of CAT formation greater than 50\%, similar to the values found in the literature for $C$. lindemuthianum (Pinto et al., 2012). These strains may be used in future studies seeking to clarify the function of CATs and their formation among different species.

In PCR analyses, the expected products were only amplified in the $C$. lindemuthianum strains using a primer pair specific to this species (García-Serrano et al. 2008). In this study, the corresponding band was amplified from strains of the Glomerella sp II group (G7-2, G8-1, G15-5, G25-1, G43-2, and G68-1) when tested with the primers specific to Glomerella sp (Barcelos et al., 2011). A pair of primers developed by Menat et al. (2012) produced amplicons in all the groups studied, and were not specific to the strains derived from scab (Colletotrichum spp group).

IRAP markers have been used to identify different species of the genus Colletotrichum (Dos Santos et al., 2012) through detection of polymorphism of the retroelement $C$. lindemuthianum 1 (RetroCl1). Strains of the $C$. lindemuthianum group formed a group following the analysis of IRAP markers. For the other groups, the S6 strain formed an individual group, near to those of C. lindemuthianum, and S2 and S5 strains formed a third group, near the S1 strain. Strains of Glomerella sp II formed individual groups, except for G85-1 and G86-1, which were in the same group. From Glomerella sp I, three strains formed one group (G68-1, G7-2, and G25-1) and, for the other, each strain formed a distinct group. The greatest dissimilarity was observed between the strains that did not cause disease and those that did; therefore, these pathogenic strains have similar characteristics as detected by the retrotransposon marker.

This study described the differences between strains of $C$. lindemuthianum and Glomerella spp that co-inhabit anthracnose lesions, as reported by Barcelos et al. (2014) and identified variability for strains of Colletotrichum spp, which are derived from scab lesions. We provide a detailed analysis of various species found in common bean, involving various traits. It should also be noted that this is the first detailed study on common bean scab and on the possible etiological agents of the disease. Studies on genetic resistance to common bean scab should be undertaken with a view towards control of the disease. Analysis of molecular phylogenetic will be able to identify different species of Colletotrichum that infect and co-inhabit lesions of anthracnose and common bean scab. These results corroborate findings in the literature that report the occurrence of different complexes of species belonging to the genus Colletotrichum, causing diseases or living as epiphytes in different hosts (Latunde-Dada et al., 1999; Damm et al., 2009; Liu et al., 2013).

\section{Conflicts of interest}

The authors declare no conflict of interest.

\section{ACKNOWLEDGMENTS}

The authors acknowledge CAPES, FAPEMIG, and CNPq for their financial support and Prof. Marisa Vieira de Queiroz for helping with the IRAP analyses.

\section{REFERENCES}

\footnotetext{
Bailey JA and Jeger MJ (1992). Colletotrichum: biology, pathology and control. CAB International, Wallingford.

Barcelos QL, Souza EA and Vaillancourt L (2011). Morphological and phylogenetic analysis of Glomerella and C. lindemuthianum strains strains from common bean anthracnose lesions. Annu. Rep. Bean Improv. Coop. 54: 224-225.
} 
Barcelos QL, Pinto JM, Vaillancourt LJ and Souza EA (2014). Characterization of Glomerella strains recovered from anthracnose lesions on common bean plants in Brazil. PLoS One 9: e90910. http://dx.doi.org/10.1371/journal.pone.0090910

Castro RA, Mendes-Costa MC and Souza EA (2006). Dimorfismo de ascósporos de Glomerella cingulata f. spp. phaseoli. Fitopatol. Bras. 31: 598-600. http://dx.doi.org/10.1590/S0100-41582006000600011

Castro-Prado MA, Querol CB, Sant'Anna JR, Miyamoto CT, et al. (2007). Vegetative compatibility and parasexual segregation in Colletotrichum lindemuthianum, a fungal pathogen of the common bean. Genet. Mol. Res. 6: 634-642.

Daboussi MJ and Capy P (2003). Transposable elements in filamentous fungi. Annu. Rev. Microbiol. 57: 275-299. http://dx.doi. org/10.1146/annurev.micro.57.030502.091029

Damm U, Crous PW and Fourie PH (2007). Botryosphaeriaceae as potential pathogens of prunus species in South Africa, with descriptions of Diplodia africana and Lasiodiplodia plurivora sp. nov. Mycologia 99: 664-680. http://dx.doi.org/10.3852/ mycologia.99.5.664

Damm U, Woudenberg JHC, Cannon PF and Crous PW (2009). Colletotrichum species with curved conidia from herbaceous hosts. Fungal Divers. 39: 45-87.

Dias MD (2002). Caracterização morfológica, Bioquímica e Patogênica de isolados de Colletotrichum spp. Em Coffea arabica L. Master's Thesis, UFLA, Lavras.

Dice LR (1945). Measures of the amount of ecologic association between species. Ecology 26: 297-302. http://dx.doi. org/10.2307/1932409

Dos Santos LV, de Queiroz MV, Santana MF, Soares MA, et al. (2012). Development of new molecular markers for the Colletotrichum genus using RetroCl1 sequences. World J. Microbiol. Biotechnol. 28: 1087-1095. http://dx.doi.org/10.1007/ $\underline{\text { s11274-011-0909-x }}$

Edgerton CW (1914). Plus and minus strains in the genus Glomerella. Am. J. Bot. 1: 244-254. http://dx.doi.org/10.2307/2435256

García-Serrano M, Laguna EA, Rodriguez-Guerra R and Simpson J (2008). Analysis of the MAT1-2-1 gene of Colletotrichum lindemuthianum. Mycoscience 49: 312-317. http://dx.doi.org/10.1007/S10267-008-0424-6

Hyde KD, Cai L, Cannon PF, Crouch JA, et al. (2009). Colletotrichum - names in current use. Fungal Divers. 39: 147-182.

Ishikawa FH, Souza EA, Read ND and Roca MG (2010). Live-cell imaging of conidial fusion in the bean pathogen, Colletotrichum lindemuthianum. Fungal Biol. 114: 2-9. http://dx.doi.org/10.1016/j.funbio.2009.11.006

Ishikawa FH, Souza EA, Shoji JY, Connolly L, et al. (2012). Heterokaryon incompatibility is suppressed following conidial anastomosis tube fusion in a fungal plant pathogen. PLoS One 7: e31175. http://dx.doi.org/10.1371/journal.pone.0031175

Junqueira NTV, Chaves GM, Zambolim L, Romeiro RS, et al. (1984). Isolamento, cultivo e esporulação de Microcyclus ulei, agente etiológico do mal das folhas de seringueira. Rev. Ceres 31: 322-331.

Kalendar R, Grob T, Regina M, Suoniemi A, et al. (1999). IRAP and REMAP: two new retrotransposon-based DNA fingerprinting techniques. Theor. Appl. Genet. 98: 704-711. http://dx.doi.org/10.1007/s001220051124

Kaufman B, Richards S and Dierig DA (1999). DNA isolation method for high polysaccharide Lesquerella species. Ind. Crops Prod. 9: 111-114. http://dx.doi.org/10.1016/S0926-6690(98)00021-1

Kimati H and Galli F (1970). Glomerella cingulata (Stonem.) Spauld. Et v. Scherenk. f. spp. phaseoli n. f., fase ascógena do agente causal da antracnose do feijoeiro. An. Esc. Super. Agric. Luiz de Queiroz 27: 411-437.

Latunde-Dada AO, O'Connell RJ, Nash C and Lucas JA (1999). Stomatal penetration of cowpea (Vigna unguiculata) leaves by a Colletotrichum species causing latent anthracnose. Plant Pathol. 48: 777-784. http://dx.doi.org/10.1046/j.13653059.1999.00405.x

Liu F, Cai L, Crous PW and Damm U (2013). Circumscription of the anthracnose pathogens Colletotrichum lindemuthianum and C. nigrum. Mycologia 105: 844-860. http://dx.doi.org/10.3852/12-315

Menat J, Cabral AL, Vijayan P, Wei Y, et al. (2012). Glomerella truncata: another Glomerella species with an atypical mating system. Mycologia 104: 641-649. http://dx.doi.org/10.3852/10-265

Mota SF, Souza EA and Dias MA (2015). Reaction of common bean and soybean cultivars to Colletotrichum spp. and Glomerella sp. strains from common bean lesions. Annu. Rep. Bean Improv. Coop. 58: 35-36.

Oliveira JA (1991). Efeito do tratamento fungicida em sementes no controle de tombamento de plântulas de pepino (Cucumis sativus L.) e pimentão (Capsicum annum L.). Masters thesis, UFLA, Lavras.

Pereira AL, Silva GS and Ribeiro VQ (2006). Caracterização fisiológica, cultural e patogênica de diferentes isolados de Lasiodiplodia theobromae. Fitopatol. Bras. 31: 572-578. http://dx.doi.org/10.1590/S0100-41582006000600006

Pinto JM, Pereira R, Mota SF, Ishikawa FH, et al. (2012). Investigating phenotypic variability in Colletotrichum lindemuthianum populations. Phytopathology 102: 490-497. http://dx.doi.org/10.1094/PHYTO-06-11-0179

Raeder U and Broda P (1985). Rapid preparation of DNA from filamentous fungi. Lett. Appl. Microbiol. 1: 17-20. http://dx.doi. org/10.1111/j.1472-765X.1985.tb01479.x

Roca MG, Davide LC, Mendes-Costa MC and Wheals A (2003). Conidial anastomosis tubes in Colletotrichum. Fungal Genet. Biol. 40: 138-145. http://dx.doi.org/10.1016/S1087-1845(03)00088-4 
Rodriguez-Guerra R, Ramírez-Rueda MT, Cabral-Enciso M, Gacía-Serrano M, et al. (2005). Heterothallic mating observed between Mexican isolates of Glomerella lindemuthiana. Mycologia 97: 793-803.

Rohlf FJ (2000). NTSYSpc, Numerical Taxonomy and Multivariate Data Analysis System, ver. 2.01. Exeter Software: Setauket, New York.

Russel PF and Rao TR (1940). On habitat and association of species of anophelinae larvae in south-eastern Madras. J. Malar. Inst. India 3: 153-178.

Santana MF, Batista AD, Ribeiro LE, de Araújo EF, et al. (2013). Terminal repeat retrotransposons as DNA markers in fungi. J. Basic Microbiol. 53: 823-827.

Schneider S, Roessli D and Excoffier L (2000). Arlequin: a software for population genetics data analysis, ver. 2.0. Software: University of Geneva, Geneva

Schoonhoven A and Pastor-Corrales MA (1987). Standard system the evaluation of bean germoplasm. CIAT.

Souza BO, Souza EA and Mendes-Costa MC (2007). Determinação da variabilidade em isolados de Colletotrichum lindemuthianum por meio de marcadores morfológicos e culturais. Cienc. Agrotec. 31: 1000-1006. http://dx.doi. org/10.1590/S1413-70542007000400009

Souza EAD, Camargo OA, Jr. and Pinto JMA (2010). Sexual recombination in Colletotrichum lindemuthianum occurs on a fine scale. Genet. Mol. Res. 9: 1759-1769. http://dx.doi.org/10.4238/vol9-3gmr863

Talamini V, Souza EA, Pozza EA, Carrijo FRF, et al. (2004). Identificação de raças patogênicas de Colletotrichum lindemuthianum a partir de isolados provenientes de regiões produtoras de feijoeiro comum. Summa Phytopathol. 30: 371-375.

Weber RWS and Webster J (1998). Stimulation of growth and reproduction of Sphaeronaemella fimicola by other coprophilous fungi. Mycol. Res. 102: 1055-1061. http://dx.doi.org/10.1017/S0953756297006011

Wicker T, Sabot F, Hua-Van A, Bennetzen JL, et al. (2007). A unified classification system for eukaryotic transposable elements. Nat. Rev. Genet. 8: 973-982. http://dx.doi.org/10.1038/nrg2165 